\title{
Composiçáo musical \\ a partir de Modelagem Sistêmica \\ e Teoria dos Conjuntos
}

\author{
Pedro Henrique Carneiro Tavares. Maria Clara de Sousa Tavares \\ Conservatório Pernambucano de Música | Orcid: 0000-0003-2225-408X \\ Instituto Federal do Sertão Pernambucano Orcid: 0000-0001-7803-687X
}

\begin{abstract}
Resumo
$\mathrm{O}$ artigo apresenta resultados de projeto de pesquisa com foco na investigação teórico-prática do processo de criação musical a partir do uso associado de modelagem sistêmica e da teoria dos conjuntos. A modelagem sistêmica, que origina-se da convergência das teorias da intertextualidade e dos sistemas composicionais, sendo a priori empregada na geraçăo de parâmetros musicais a partir de um intertexto. A teoria dos conjuntos, tendo origem na teoria matemática, está sendo utilizada na regência da organização dos parâmetros musicais, no âmbito da criação de obras musicais originais.
\end{abstract}

Palavras-chave: Composição musical, Modelagem sistêmica, Teoria dos conjuntos.

\section{Musical composition using Systemic Modeling and Set Theory}

\begin{abstract}
The article presents results of a research project focusing on the theoretical-practical investigation of musical creation process by associated use of systemic modeling and set theory. Systemic modeling, which originates from the convergence of theories of intertextuality and compositional systems, being employed in the generation of musical parameters from an intertext. The set theory, originating in mathematical theory, being used in the organization of musical parameters, within the scope of the creation of original musical works.
\end{abstract}

Keywords: Musical composition, Systemic modeling, Set theory.

\section{Composición musical a partir del modelado sistémico y la teoría de conjuntos}

\section{Resúmen}

El artículo presenta los resultados de un proyecto de investigación centrado en la investigación teórico-práctica del proceso de creación musical a partir del uso asociado del modelado sistémico y la teoría de conjuntos. El modelado sistémico, que se origina de la convergencia de teorías de intertextualidad y sistemas compositivos, siendo a priori empleado en la generación de parámetros musicales a partir de un intertexto. La teoría de conjuntos, originada en la teoría matemática, está siendo utilizada en la conducción de la organización de parámetros musicales, en el ámbito de la creación de obras musicales originales.

Palabras Clave: Composición musical, Modelización sistémica, Teoría de conjuntos. 


\section{Tntrodução}

Assim como muitas áreas do conhecimento, particularmente aquelas ligadas a processos criativos, no campo de composição musical temos a presença dos mais diversos tipos de interaçốes, e inspirações, com outras áreas do conhecimento. Exemplos dessas interaçôes, em procedimentos ligados à criação musical, são bastante variados, porém podemos destacar o diálogo com a linguística e a matemática, dentre outras possíveis. A matemática na música está presente em uma infinidade de elementos, desde relaçôes intervalares a procedimentos utilizados na construção musical, particularmente alguns dos séculos XX e XXI. Relaçôes com a linguística, por exemplo, apresentam-se na organização do discurso musical em frase, períodos, etc.

Neste artigo são apresentados resultados, e discussóes, decorrentes de projeto de pesquisa1, focado na investigação teórico-prática de aplicaçóes do uso associado de modelagem sistêmica e da teoria dos conjuntos, no processo de criação musical. Tal proposta apresenta um caráter interdisciplinar, envolvendo intertexto, matemática e composição musical. $\mathrm{O}$ texto estrutura-se da seguinte maneira: uma breve introduçáo e fundamentaçáo das teorias previamente citadas; detalhamentos sobre materiais e métodos utilizados, provenientes das teorias em questáo; o relato proveniente do desenvolvimento do projeto, ou seja, relato da aplicação prática realizada na elaboração de uma obra musical original; e, por fim, conclusôes e consideraçôes finais acerca do trabalho realizado. Serão agora estabelecidos, e fundamentados, os principais conceitos nos quais está baseado o trabalho, modelagem sistêmica e teoria dos conjuntos.

\section{Modelagem sistêmica}

Com a finalidade de fundamentar e estabelecer conceitos acerca da modelagem sistêmica, utilizamos os trabalhos desenvolvidos por Liduino Pitombeira, pelo fato do mesmo ser referência quando trata-se da temática. Segundo Pitombeira (2016), a modelagem sistêmica tem origem a partir da convergência entre a teoria da intertextualidade e a teoria dos sistemas composicionais. Inicialmente introduzimos conceitos referentes aos sistemas composicionais, sobre processos intertextuais, e, em seguida, acerca da modelagem sistêmica.

Um sistema composicional pode ser definido como "um conjunto de diretrizes que coordenam a utilização e interconexão de parâmetros e materiais musicais, com o propósito de produzir obras musicais" (PITOMBEIRA, 2016. p.105), desta maneira podemos afirmar que os sistemas são constituídos por um conjunto de definições, e que tais definições "tratam da utilização de parâmetros musicais, ou seja, definem o perfil genérico dos objetos e suas relaçóes de interconexão" (PITOMBEIRA, 2016. p.105). Podemos afirmar que as referidas definiçóes configuram uma etapa, de caráter parcial, ou inicial, dentro do planejamento para a elaboração de uma obra musical original. A produção de uma obra em si requer uma fase posterior de planejamento composicional, etapa na qual "são atribuídos valores particulares aos objetos e às relaçóes” (PITOMBEIRA, 2016. p.105).

Pitombeira sugere que os sistemas composicionais sejam tipificados em: abertos, semiabertos e retroalimentados.

1 Projeto PIBIC (IFSertáo-PE), aprovado pelo edital 67/2019. Desenvolvido entre 01/07/2020 e $28 / 02 / 2021$. 
O sistema aberto apresenta entrada e saída. É o caso dos sistemas que manipulam intertextos, modificando-os através de operaçôes nos parâmetros ou alterando a relação temporal entre os materiais. O sistema semiaberto apresenta somente a saída. É o caso dos sistemas que geram dados através de processos determinísticos ou indeterminísticos (probabilísticos). O sistema retroalimentado tem os dados da saída reintroduzidos na entrada. É o caso dos sistemas dinâmicos não lineares (caos), que são efetivados computacionalmente por processos iterativos. (PITOMBEIRA, 2016. p.106)

O processo de intertextualidade pode ocorrer de diversas maneiras, tais como, por exemplo, citaçóes e transformaçóes de um outro texto. De maneira geral, podemos classificar o processo intertextual em dois tipos: do tipo literal e do tipo abstrato. É importante ressaltar que, tal como em diversas outras classificaçóes, gradaçôes entre os tipos definidos são possíveis. No tipo literal o intertexto "é utilizado literalmente ou sofre transformações que não afetam sua integridade superficial, sendo, portanto, reconhecível” (PITOMBEIRA, 2016. p. 107), dentro deste tipo estão presentes "as transformaçóes motívicas de transposição, inversão, expansão e contração temporal, expansão e contração intervalar, deslocamento pontual de oitava e conversão, bem como a Variação, a Citação, a Paródia e o Pastiche" (PITOMBEIRA, 2016. p. 107-108). No tipo abstrato o intertexto "sofre modificaçôes radicais ou é utilizado somente em seus aspectos estruturais e profundos" (PITOMBEIRA, 2016. p. 108), estão inclusas nas modificações radicais "as transformaçóes motívicas de retrogradação, simplificação/complexificação, fixação paramétrica, filtragem, permutação e fragmentação, bem como as ferramentas de Bloom/Korsyn e Straus" (PITOMBEIRA, 2016. p. 108).

Estabelecidos alguns parâmetros e definiçōes iniciais, sobre sistemas composicionais e sobre intertextualidade, prosseguimos para a modelagem sistêmica. Uma proposta de definição apresentada por Pitombeira é "uma metodologia pré-composicional que consiste no exame dos aspectos estruturais profundos de um intertexto, no intuito de detectar o sistema composicional subjacente que lhe deu origem" (2016. p. 110). Em outras palavras, a modelagem sistêmica "trata basicamente da desmontagem de uma obra musical, a partir de certas perspectivas analíticas, com a finalidade de identificar uma estrutura primordial hipotética denominada sistema composicional" (PITOMBEIRA, 2014. p. 70), este sistema composicional é utilizado para a escrita de uma obra original, ou obras originais.

Ao considerarmos as perspectivas analíticas, trazidas na citação anterior, é importante acrescentar que elas podem ser bastante amplas. A partir de textos tais como Castro-Lima et al. (2018a e 2018b), Chrispin et al. (2019) e Pascale et al. (2020), percebe-se que, muito além de uma simplificação equivocada do que por ventura pode-se pensar ao tratar-se da estrutura interna da obra, assumindo por isso apenas sua estrutura formal e/ou fraseológica, pode-se investigar, também, acerca de diversos parâmetros escolhidos pelo compositor, como, por exemplo, contornos melódicos, classes de notas, texturas, dinâmicas, elementos rítmicos, dentre outros. Assim, assumimos que a obra original será aparentada, ainda que podendo ter maior ou menor grau de abstração, em determinados parâmetros determinados pelo compositor. Nas palavras de Pitombeira:

A modelagem sistêmica, aplicada à composição musical, é uma modalidade de intertextualidade abstrata, na qual se busca identificar o sistema composicional de uma determinada obra com a finalidade de planejar uma nova obra, aparentada com a original somente em alguns aspectos profundos (2016. p. 110). 
Pitombeira descreve o processo de modelagem em três etapas: a escolha do(s) parâmetro(s), a análise e a generalização, que "consiste em desprezar os valores particulares dos objetos e concentrar-se somente nas relaçóes" (2016. p. 110). Após este processo passa-se ao planejamento composicional, podendo ser igualmente dividido em três etapas: a particularização dos valores dos parâmetros, a aplicação desses valores no contexto musical de registro e extensão instrumental, e a complementação paramétrica, aonde "parâmetros não especificados no sistema composicional são livremente escolhidos pelo compositor" (2016. p. 111).

\section{Teoria dos conjuntos}

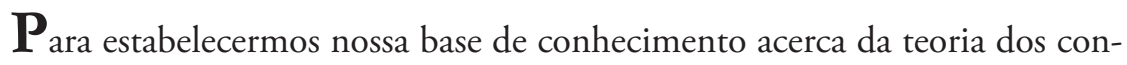
juntos iniciaremos pela teoria matemática, a teoria original, e, em seguida, sua aplicação em música, chamada de teoria dos conjuntos de classes de nota. Tavares (2020) cita que o surgimento da teoria remete à discussóes acerca de questóes conceituais sobre o significado de número. Stewart (2014) nos informa que, em 1872, Dudekind apresenta tópicos acerca da questão em sua obra Stetigkeit und Irrationale Zablen (Continuidade e números irracionais), e novamente, em 1888, no trabalho Was Sind und was Sollen die Zahlen? (O que são e o que significam os números?), aonde ele "expõe sérias lacunas nas fundações lógicas do conjunto dos números reais” (STEWART, 2014. p. 309). Abordando a questáo, Gottlob Frege propóe uma associação de números com o processo de contagem, associação esta que exerceu papel fundamental na elaboração da teoria de Georg Cantor sobre números transfinitos, que basicamente tratam de infinitos de tamanhos diferentes.

Em 1883, Georg Cantor publicou um artigo sobre teoria dos conjuntos. Ele desenvolveu o artigo para abordar as questóes matemáticas e filosóficas associadas à teoria dos conjuntos transfinitos. Em 1874, Cantor provou a existência de conjuntos infinitos que têm magnitudes diferentes e distintas. Ele demonstrou como contar conjuntos infinitos, como determinar potências e como definir equivalência2 (BATCHELOR, 2002. p. 20).

De acordo com Tavares (2020) e Stewart (2014), Cantor é considerado uma referência ao se tratar de teoria dos conjuntos. Ele conceitua um conjunto "como uma coleção de objetos, que são seus membros" (TAVARES, 2020. p. 2), e seu trabalho "levou a progressos importantes, incluindo um sistema coerente, embora não ortodoxo, de números infinitos" (STEWART, 2014. p. 330). Halmos (2017) reafirma que conjuntos são constituídos de elementos e que o principal conceito da teoria dos conjuntos é o de pertencimento, ou seja, se x pertence a A logo x é um elemento de A. Podemos realizar operaçóes com os conjuntos, tais como uniâo $(\mathrm{U})$, que de maneira simples podemos definir como a soma de todos os membros presentes nos conjuntos envolvidos, e a interseção $(\cap)$, que, igualmente de forma resumida, resulta nos membros que necessariamente encontram-se representados em todos os conjuntos envolvidos.

No campo musical, a teoria aparece como uma ferramenta analítica para músicas atonais. Autores como Kostka (2018) e Tavares (2020) citam Allen Forte como uma re-

2 In 1883, Georg Cantor published a paper about set theory. He developed the paper to address the mathematical and philosophical issues associated with transfinite set theory. In 1874, Cantor had proved the existence of infinite sets that have different and distinct magnitudes. He demonstrated how to count infinite sets, how to determine powers, and how to define equivalence. (BATCHELOR, 2002. p.20). Tradução própria. 
ferência no assunto, através de seu trabalho A estrutura da música atonal ${ }^{3}$, com primeira publicação em 1973. Por focar sua atenção nas classes de nota, chamamos essa aplicação musical de teoria dos conjuntos de classes de nota. De maneira simples, podemos afirmar que uma nota se refere a uma altura sonora específica, como por exemplo Dó3, enquanto classe de nota remete a um grupo de alturas que compartilham o mesmo nome, ou classe, por exemplo todos as notas com nome Dó. De acordo com Kostka:

Reconheceu-se que a música atonal frequentemente alcançava um certo grau de unidade através do uso recorrente de um novo tipo de motivo. Esse novo tipo de motivo recebeu vários nomes, incluindo célula, célula básica, conjunto, conjunto de notas, conjunto de classes de notas e sonoridade referencial. Pode aparecer melodicamente, harmonicamente ou como uma combinação dos dois. ${ }^{4}$ (KOSTKA, 2018. p.171).

Schuijer (2008. p.4) reforça o exposto por Kostka ao afirmar que a teoria dos conjuntos de classes de notas aborda a noção de coerência musical, ou seja, ela busca coerência nas relações entre várias combinaçôes de notas. $\mathrm{O}$ autor complementa a definição acerca da teoria:

A teoria dos conjuntos de classes de notas é uma aplicação musical da teoria dos conjuntos matemáticos. Assim como o último, define um conjunto como uma coleçâo de coisas e refere-se a essas coisas como elementos do conjunto. (...) um conjunto é definido apenas por seus elementos, não por um arranjo particular desses elementos ou por suas quantidades. (...) O que há de especial na teoria dos conjuntos de classes de notas é o tipo de elemento com o qual ela lida: a classe de nota. ${ }^{5}$ (SCHUIJER, 2008. p. 29).

Da mesma maneira que os conjuntos, na matemática, podem ser submetidos a determinadas operaçôes, os conjuntos de classes de nota também podem ser trabalhados a partir de determinadas operaçóes. Dentre as mais comumente encontradas citamos a transposição, inversão e multiplicação. Todas estas três operações citadas encontram-se ilustradas no processo de elaboração da obra original tratada neste trabalho, sendo expostas no tópico "desenvolvimento do processo", mais adiante neste texto.

\section{Material e Métodos}

$\mathbf{E}_{\text {xpomos agora acerca de materiais e metodologias utilizados no desenvol- }}$ vimento do trabalho de elaboração da obra original. Em relação ao material, estabelecemos previamente que a modelagem sistêmica trabalha com processos intertextuais. Tal processo concretiza-se ao utilizar-se uma obra prévia como base para, a partir de análise realizada na mesma, utilizar estruturas e parâmetros da obra como modelo para a elaboração da obra 3 Título original em inglês: The Structure of Atonal Music. Tradução própria.

4 It was recognized that atonal music often achieved a certain degree of unity through recurrent use of a new kind of motive. This new kind of motive was given various names, including cell, basic cell, set, pitch set, pitch-class set, and referential sonority. It could appear melodically, harmonically, or as a combination of the two. (KOSTKA, 2018. p. 171). Tradução própria.

5 Pitch-class set theory is a musical application of mathematical set theory. As with the latter, it defines a set as a collection of things, and it refers to these things as the elements of the set. (...) a set is defined by its elements only, not by a particular arrangement of these elements or by their quantities. (...) What is special about pitch-class set theory is the type of element it deals with: the pitch class. (SCHIJER, 2008. p. 29). Tradução própria. 
original. Em outras palavras, como material básico utilizamos uma composição musical preexistente como texto original, para elaborar uma obra original, nosso intertexto, utilizando ferramentas e métodos combinados da modelagem sistêmica e teoria dos conjuntos. A obra musical escolhida como texto de base foi Vassourinhas, tradicional frevo de rua composto por Mathias da Rocha e Joana Baptista.

Expomos agora acerca das ferramentas e métodos utilizados, iniciando pela modelagem sistêmica e, em seguida, a teoria dos conjuntos de classes de nota. Como exposto por Pitombeira (2016), o processo de modelagem sistêmica pode ser descrito em três etapas, são elas: a escolha do(s) parâmetro(s), a análise e a generalização. Para melhor compreensão desta utilização da modelagem sistêmica investigamos trabalhos acerca de composiçóes realizadas a partir do uso da mesma, particularmente Castro-Lima et al. (2018a e 2018b), Chrispin et al. (2019) e Pascale et al. (2020). De acordo com os estudos citados, essas três etapas desembocam na elaboração de um modelo sistêmico, ou em outras palavras, um sistema composicional hipotético, o qual serve como base para a etapa posterior de planejamento composicional. Em outras palavras:

Na Modelagem Sistêmica, uma determinada obra é analisada a partir de determinados parâmetros de maneira que se possa propor um modelo do funcionamento da obra de acordo com os parâmetros utilizados. Esse modelo é chamado de Sistema Composicional, e pode ser constituído de uma série de definiçóes ou modelos matemáticos. A partir deste Sistema Composicional são compostas novas obras, em uma fase denominada Planejamento Composicional. (CASTRO-LIMA et al. 2018a. p.1).

Os métodos de análise empregados foram a análise estrutural, abordando os elementos formais e fraseológicos, para o esqueleto estrutural do nosso sistema composicional hipotético, e a análise da coleção de alturas sonoras, para gerar novas alturas a partir do trabalho com a teoria dos conjuntos.

Seguindo para a etapa de planejamento composicional podemos, semelhantemente à modelagem sistêmica, dividi-la em três etapas. De acordo com de acordo com Pitombeira (2016) elas podem ser: a particularização dos valores dos parâmetros, a aplicação desses valores no contexto musical de registro e extensão instrumental, e a complementação paramétrica. É nesta etapa, planejamento composicional, que estamos empregando ferramentas e procedimentos oriundos da teoria dos conjuntos de classes de nota. Inicialmente reorganizamos as coleçóes de alturas, obtidas da obra analisada, em conjuntos, as colocando na melhor ordem normal. De acordo com Kostka (2018) e Tavares (2020) podemos definir a ordem normal como uma arrumação das classes de nota a qual abrange o menor intervalo possível, em outras palavras, a mais compacta possível. A melhor ordem normal é realizada a partir da comparação do conjunto com seu conjunto equivalente por inversão, inversão do conjunto original, desta forma encontrando a maneira mais compacta possível de apresentar o mesmo. A partir dos conjuntos trabalhamos as alturas de diversas maneiras, dentre as quais destacam-se: a transposição, a inversão e a multiplicação. Para construção das frases e períodos adotamos a mesma metodologia utilizada por Tavares:

$\mathrm{Na}$ construçáo das frases e períodos adotamos o procedimento de que, de cada conjunto utilizado, ao menos uma nota pertencesse também a outro conjunto, desta maneira dentro de cada período fazemos com que todas as notas estejam conectadas. $\mathrm{Na}$ transiçáo entre períodos tomamos a liberdade de abandonar tal procedimento, de forma a contribuir para a percepção de uma maior separação entre os mesmos, e assim, contribuindo para nosso discurso musical almejado. (2020. p. 11). 
Tal metodologia é adaptada, de forma a se adequar melhor à nossa proposta, cujo foco reside na construção dos motivos. No nosso caso, portanto, a citação anterior pode ser reescrita como: $\mathrm{Na}$ construção dos motivos adotamos o procedimento de que, de cada conjunto utilizado, ao menos uma nota pertencesse também a outro conjunto, conectando os conjuntos dentro do motivo. Abandonamos tal procedimento para a transiçáo entre motivos, criando uma maior separação entre os mesmos, e assim, contribuindo para nosso discurso musical almejado.

\section{Desenvolvimento do processo}

Expomos agora detalhamentos acerca das etapas desenvolvidas na elaboração da peça musical original a partir da proposta apresentada. A análise da peça preexistente escolhida, Vassourinhas, serviu de base para a criação do sistema composicional hipotético, que desenvolvemos para a escrita de uma composição original, tal qual propóe a modelagem sistêmica. No aspecto formal, e fraseológico, identificamos as seçóes, frases e motivos, também denominados incisos, a depender do livro ou método adotado como referência. É possíveis mais de um tipo de padrão de identificação, ou de nomeclatura. Optamos pela adoção de letras (a, b, c...) com a utilização do acréscimo de apóstrofos (') a cada nova variante da frase ou motivo, outra opção, a título de exemplificação, seria a utilização de números $(1,2,3 \ldots)$ ao invés dos apóstrofos a cada nova variante daquela frase, ou motivo. Desta maneira, se temos uma frase a que é reapresentada com variação, identificamos a mesma como frase a'. A partitura analisada encontra-se ilustrada a seguir, através da Figura 1.

A partir da análise ilustrada na Figura 1, temos estabelecidas as primeiras definiçóes no nosso sistema composicional hipotético, são elas:

- Peça tem estrutura formal ternária, seguindo o modelo $A-B-A$.

- Seção A segue a estrutura: Frase a, formada pelos motivos a e b; Frase a, repetida com transposição; Frase a', formada pelos motivos a e c; Frase b, formada pelos motivos b’ e b”. Todas as frases desta seção apresentam duração de quatro compassos.

- Seção B segue a estrutura: Frase c, formada pelos motivos d, d', d' e d"; Frase c', formada pelos motivos d"', d"', d" e d"'. Todas as frases desta seção apresentam duração de oito compassos.

- Ritmicamente, as notas da seção A são mais rápidas enquanto as da seção B são mais longas.

Quanto a análise da coleção de alturas sonoras, optamos por analisar os conjuntos referentes aos motivos (a, b, c e d). As variaçóes, tal qual a', constituem-se como apresentaçóes retrabalhadas, variadas, dos motivos originais, e, portanto, não são utilizadas como base para este trabalho. Uma exceção encontra-se no trabalho referente ao motivo d, pois todas as apariçóes do mesmo, exceto a primeira, contém quatro notas, e, neste caso, escolhemos calcular o conjunto considerando-o com quatro notas. 
Figura 1: Vassourinhas

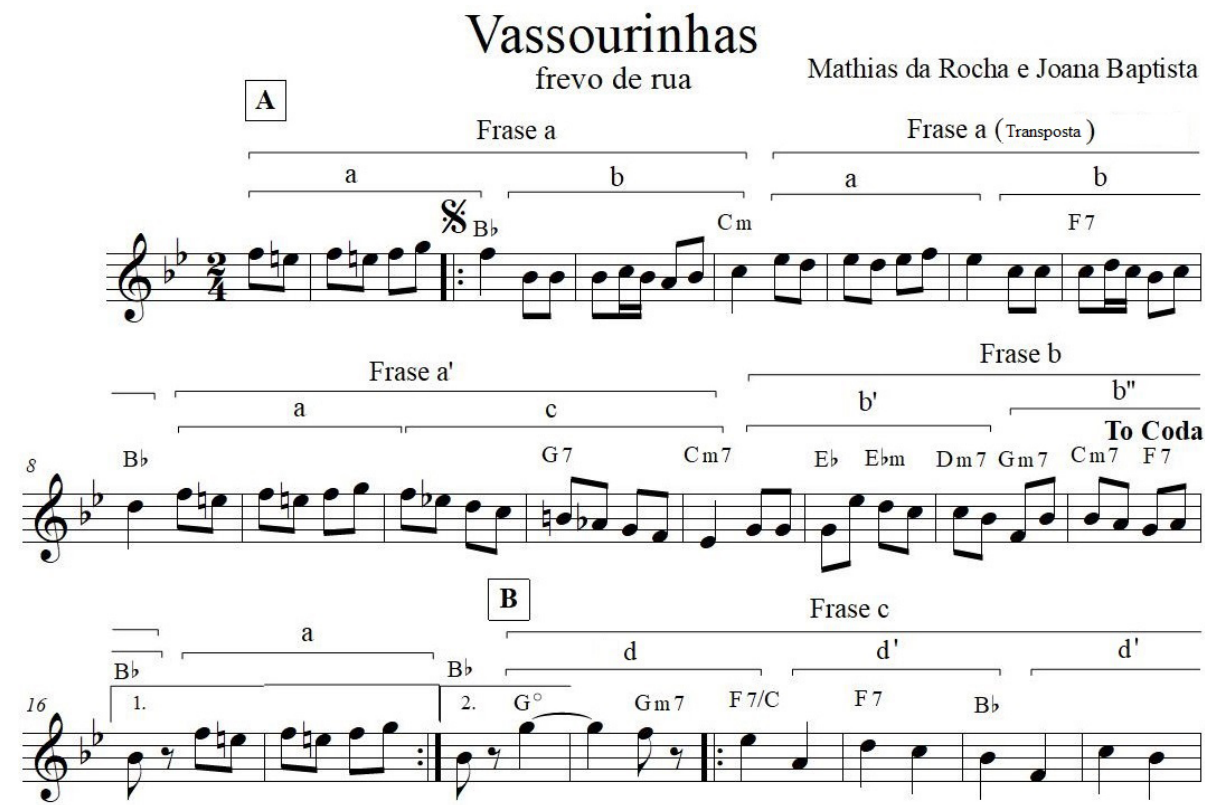

Frase c'
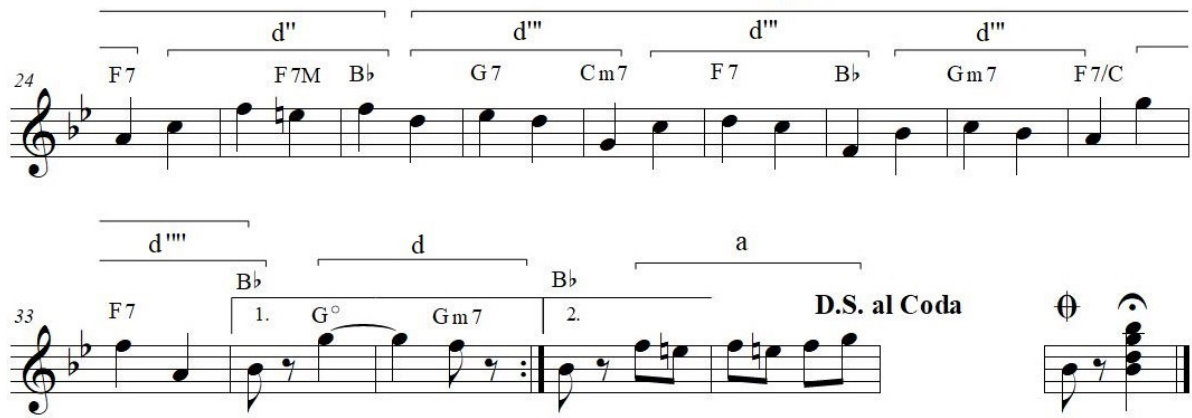

Fonte: Editoração e análise própria a partir de Gomes de Sá (1998)

Na Figura 2 encontra-se ilustrado o procedimento realizado para encontrar o conjunto de classes de nota do motivo a. O procedimento é idêntico para identificaçáo dos conjuntos remetentes aos demais motivos, ou seja, aos motivos b, c, e d. Foram realizados os seguintes passos, na ordem apresentada: identificação da coleçáo de alturas presentes no motivo; reorganização das alturas para encontrar a ordem normal; inversão do conjunto; comparação para encontrar a melhor ordem normal; nome do conjunto de classe de nota resultante.

Os números utilizados seguem o princípio da Teoria Pós-Tonal, tal como exposto por Straus (2013), e, portanto, referem-se ao intervalo entre classes de nota, medido em número de semitons. O nome do conjunto é feito "a partir de números associados a sua melhor ordem normal" (Tavares, 2020. p.6), partimos da classe de nota inicial, como zero, e indicamos as demais de acordo com o número de semitons presentes no intervalo entre a classe de nota inicial e elas. 
Figura 2: Identificando o conjunto de classes de nota do motivo $a$
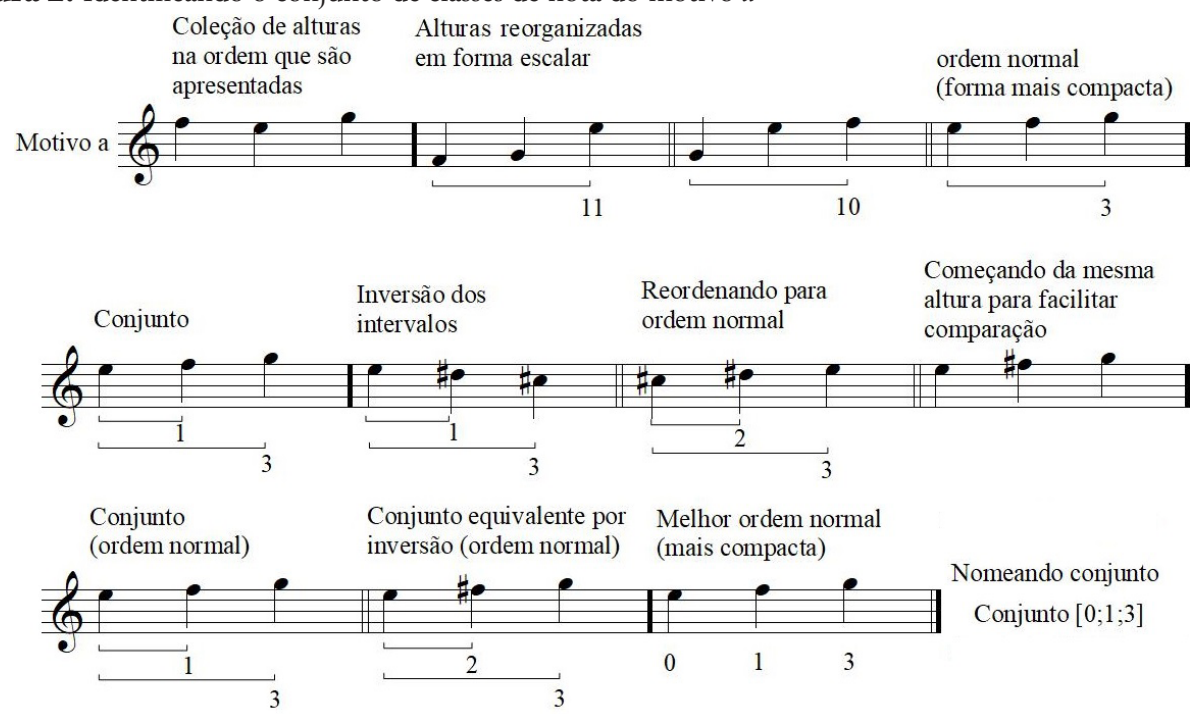

Fonte: Elaboração própria.

De acordo com o exposto, estabelecemos que o motivo $a$ trabalha com o conjunto $[0 ; 1 ; 3]$. Utilizando o mesmo procedimento temos o motivo $b$ empregando, igualmente, o conjunto [0;1;3], o motivo $c$ com o conjunto $[0 ; 1 ; 3 ; 4 ; 6 ; 8 ; 9]$ e o motivo $d$ com o conjunto [0;2;4;7]. Assim chegamos às definiçóes finais para nosso sistema:

- Alturas sonoras do Motivo a são construídas a partir do Conjunto [0;1;3].

- Alturas sonoras do Motivo $b$ são construídas a partir do Conjunto [0;1;3].

- Alturas sonoras do Motivo $c$ são construídas a partir do Conjunto $[0 ; 1 ; 3 ; 4 ; 6 ; 8 ; 9]$.

- Alturas sonoras do Motivo $d$ são construídas a partir do Conjunto $[0 ; 2 ; 4 ; 7]$.

Optamos por nomear nossa composição original de Sombrinha, com certa referência à peça Vassourinhas. A obra foi escrita para guitarra solo, utilizando auxílio da técnica de digitação com as duas mãos, chamada de Tapping. A estrutura de peça segue as definiçóes estabelecidas a partir da análise de Vassourinhas, assim como os motivos são construídos a partir dos conjuntos definidos anteriormente. Ressaltamos nossa metodologia, previamente citada, de que os conjuntos estejam interligados por ao menos uma nota comum dentro dos motivos, e separados na transição entre motivos.

A figura 3 ilustra tal procedimento nos compassos iniciais da peça, nela percebemos também que, apesar de compartilhar o mesmo conjunto, [0;1;3], os motivos a e b foram construídos de maneira a serem contrastantes entre si. Os conjuntos estão destacados com cores diferentes, para facilitar a visualização. Foram utilizadas aqui tanto transposição, iniciar o conjunto a partir de outra altura, como de Lá-Sib-Dó (em azul na Figura 3) para Sol-Láb-Sib (em vermelho), quanto inversão, Lá-Sib-Dó guarda a estrutura 1semitom-2semitons enquanto Fá-Sol-Láb (em verde) guarda a relação 2semitons-1 semitom. Podemos dizer, apenas a título de comparação uma vez que trata-se ainda do mesmo conjunto, que $[0 ; 1 ; 3]$ se apresenta como [0;2;3]. A frase a é logo reapresentada utilizando-se de transposição, tal como na peça Vassourinhas, igualmente ilustrado na Figura 3. 
Figura 3: Sombrinha, compassos iniciais

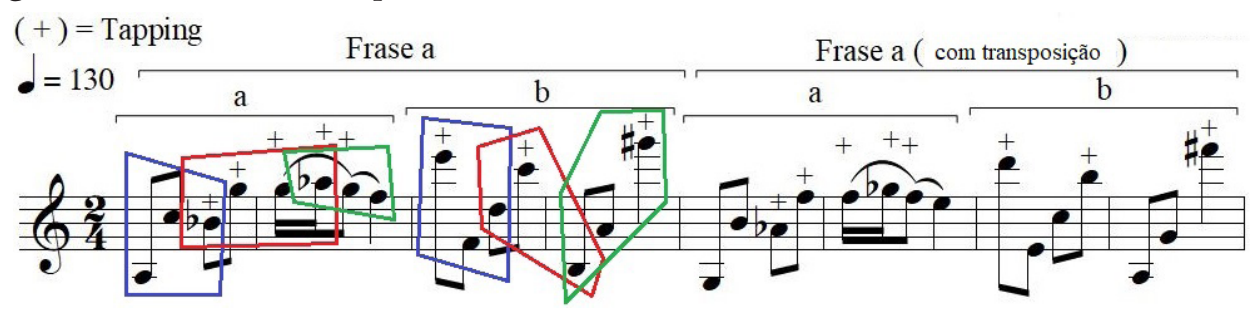

Fonte: Elaboração própria.

O motivo $c$ trabalha com o conjunto [0;1;3;4;6;8;9], os motivos $b$ ' e $b$ ", que compóem a frase final da seção são variaçóes do motivo $b$ e, portanto, utilizamos o conjunto $[0 ; 1 ; 3]$. Para as variaçôes de $b$ utilizamos a operação de multiplicação, que consiste de ampliar os intervalos por um fator $n$ mantendo todos os resultados em mod12. Desta maneira o conjunto $[0 ; 1 ; 3]$ se transforma em $[0 ;(\mathrm{n} .1) \bmod 12 ;(\mathrm{n} .3) \bmod 12]$, para $b$ ' definimos $n=2$, resultando $[0 ; 2 ; 6]$, enquanto para $b$ " definimos $n=3$, resultando [0;3;9]. Na Figura 4 encontram-se ilustrados os motivos $c, b^{\prime}$ e $b^{\prime \prime}$, com os conjuntos em destaque gráfico.

Figura 4: Sombrinha - motivos $c, b^{\prime}$ e $b^{\prime \prime}$

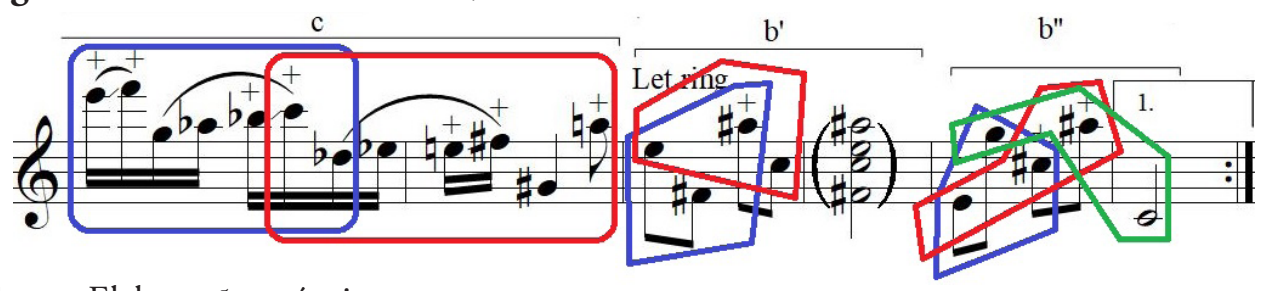

Fonte: Elaboração própria.

$\mathrm{Na}$ construção da parte $\mathrm{B}$, que baseia-se sobre o motivo $d$ e suas variaçóes, mantivemos o ritmo básico em semínimas, utilizando uma única aparição do conjunto $[0 ; 2 ; 4 ; 7]$ por motivo. O último motivo, $d$ '”, apresenta uma variação rítmica para contribuir com a sensação de finalização, de cadência. Os motivos foram construídos baseados no uso das alturas distribuídas de maneira a criar um arpejo do tipo Maior com nona (M9), o qual recomendamos, em termos de interpretação, deixar as notas soarem somando-se até o final do motivo. Tal tipo de construção contribui para o contraste entre as seçóes A e $\mathrm{B}$, uma vez que na parte $\mathrm{A}$ temos mais movimentação rítmica e um caráter com maior ênfase melódica, ainda que não sobre abordagem tradicional do tipo cantabile ${ }^{6}$, enquanto a parte B apresenta um caráter de ênfase harmônica, através dos arpejos. Desta maneira há significativa mudança de sonoridade entre as seçóes, proporcionando momentos distintos dentro da peça musical. As frases que compóem a seção B, frases c e c', constituem-se de quatro motivos cada, optamos por iniciar cada motivo dentro das frases com uma altura que, juntas, formassem as classes de nota do conjunto [0;2;4;7], assim gerando ainda mais

6 Melodia construída com características vocais, ou cantáveis, ainda que se trate de uma peça instrumental. Empregando, por exemplo, um âmbito menor, náo ultrapassando em muito uma oitava, mais graus conjuntos que saltos, etc. 
unidade estrutural dentro da seção B. Desta forma a frase $\mathrm{c}$ trabalha com quatro motivos, construídos a partir de [0;2;4;7], e cada motivo inicia com uma classe, no caso Si-Dó\#-Ré\#Fá\#, que, juntas, também formam o conjunto [0;2;4;7]. Trabalho semelhante é realizado na frase c', através do início de cada motivo com as classes Dó\#-Ré\#-Fá-Sol\#. Pode-se observar tal construção, do trabalho com o motivo d, através da Figura 5, que apresenta a partitura analisada da peça composta, Sombrinha.

Figura 5: Sombrinha - partitura analisada.

\section{Sombrinha}
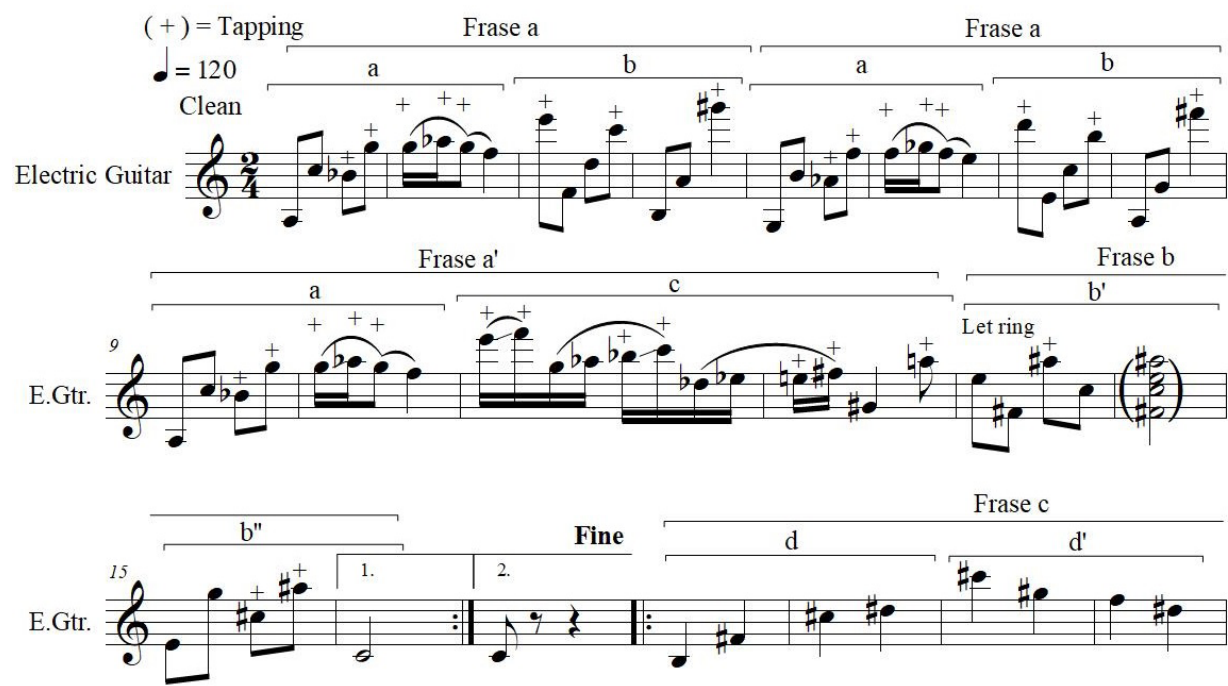

Frase $c^{\prime}$
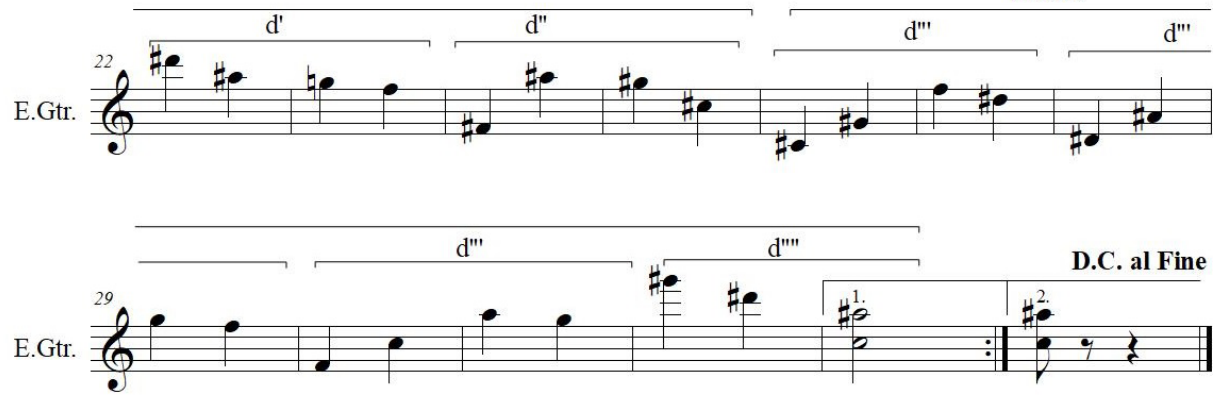

Fonte: Elaboração própria. 


\section{Conclusóes}

A investigação realizada apresentou caráter interdisciplinar, relacionando diferentes áreas do conhecimento, destacadamente intertextualidade, matemática e composição musical. Nos propomos a estudar a associação de duas teorias, modelagem sistêmica e teoria dos conjuntos, aplicadas ao processo de criação musical. Empregamos a modelagem sistêmica na geração de parâmetros musicais a partir de um intertexto, gerando um sistema composicional hipotético, a partir do qual baseamos a escrita de uma obra original. A teoria dos conjuntos foi aplicada na regência da organização dos parâmetros musicais, destacadamente alturas sonoras, através de trabalho com classes de nota.

A partir dos resultados obtidos, expostos através deste artigo, percebemos uma grande afinidade na combinação das duas teorias. Através do uso combinado das mesmas, elaboramos uma metodologia e construímos uma obra musical original, Sombrinha, a partir de uma peça escolhida como intertexto, Vassourinhas. Nossos procedimentos metodológicos ilustram apenas uma possibilidade, dentre várias igualmente possíveis, do uso combinado das teorias estudadas.

Aqui foram abordadas relaçóes advindas das áreas já citadas, são elas: a intertextualidade através da qual, somada à atenção dada em questôes fraseológicas, dialogam com a linguística; a teoria dos conjuntos como elemento que estabelece relação com a matemática; e a composição musical em si, ou, em outros termos, elementos da área de música. É inegável que a parcela exposta aqui, em termos do que pode ser desenvolvido na interação entre música, linguagem e matemática, é mínima. Quantas outras teorias matemáticas não poderiam servir de base a processos de criação musical? Ou até a operaçóes realizadas dentro da própria teoria dos conjuntos de classes de nota? Quantos elementos linguísticos não oferecem ricas possibilidades para o planejamento estrutural de uma composição musical?

Em si, a relação entre essas três áreas já é bastante rica e oferece espaço de expansão, porém é nosso intuito abranger a interdisciplinaridade de forma ainda mais ampla. O quanto a física poderia oferecer, no sentido de novas opçóes, para o campo musical? Partimos da hipótese que muito, destacadamente por englobar áreas tão variadas desde a astrofísica, a física clássica de maneira geral, a física quântica, etc. O quanto outras artes podem ainda oferecer ao campo da música? Igualmente supomos que muito, por abarcar tantas manifestaçôes diferentes. Ressaltamos que nos referimos a novas possibilidades, pois casos dessas interdisciplinaridades específicas, física e música ou outras artes e música, já foram efetuadas.

Considerando todo o exposto, esperamos incentivar novas pesquisas não apenas de outras abordagens, no âmbito de música, do uso das teorias desenvolvidas ao longo deste presente trabalho, mas, também, de investigaçóes interdisciplinares das mais diversas formas, que possam se relacionar com música de forma ampla, não apenas na criação musical. 


\section{Referências}

BATCHELOR, John H. The History and Evolution of the Concept of Infinity. 2002. Disponível em: https://www.academia.edu/15202414/The History and Evolution of the Concept of Infinity?email work card=title. Acesso em: 17/09/2019.

CASTRO-LIMA, Marcel; PITOMBEIRA, Liduino. Composição de Caldeirão da Santa Cruz do Deserto a partir da Modelagem Sistêmica do Ponteio n.26 de Camargo Guarnieri. In: Anais do XXVIII Congresso da ANPPOM. 2018a. Disponível em: https://www.academia.edu/42077409/Composi\%C3\%A7\%C3\%A3o de Caldeir\%C3\%A3o da Santa_Cruz do Deserto_a partir da_Modelagem Sist\%C3\%Aamica_do_Ponteio_n_26_de_Camargo_Guarnieri. Acesso em: 19/08/2020.

CASTRO-LIMA, Marcel; PITOMBEIRA, Liduino. Planejamento composicional de Quadrilha, para quarteto de cordas, a partir da modelagem sistêmica do Ponteio no 21 de Camargo Guarnieri. MUSICA THEORICA. Salvador: TeMA, 2018b. p.175-202.

CHRISPIM, Leandro; PITOMBEIRA, Liduino. Composição da peça Lauterium de Leandro Chrispim a partir da modelagem sistêmica de Urano das Cartas Celestes II de Almeida Prado. In: Anais do XXIX Congresso da ANPPOM. 2019. Disponível em: https://www.academia.edu/42077309/Composi\%C3\%A7\%C3\%A3o da pe\%C3\%A7a_Lauterium_de_Leandro_Chrispim_a_partir_da_modelagem_sist\%C3\%Aamica de Urano das Cartas Celestes II de Almeida Prado. Acesso em: 19/08/2020.

GOMES DE SÁ, Luiz Guimarães. Songbook de Frevos. Vol. 1. Recife: Prefeitura da Cidade do Recife - Secretaria de Cultura e Turismo, 1998.

HALMOS, Paul R. Naive set theory. New York: Dover Publications, 2017.

KOSTKA, Stefan M; SANTA, Matthew. Materials and techniques of post-tonal music. 5.ed. New York: Routledge, 2018.

PASCALE, Rodrigo; USAI, Claudia; KÜHN, Max; PITOMBEIRA, Liduino. Composição de Cinco Mulheres a partir da modelagem sistêmica do Prelúdio no 1 para piano de Claudio Santoro. In: Anais do $1^{\circ}$ Colóquio de Pesquisa do PPGM-UFRJ. 2020. Disponível em: https://www.academia.edu/43648911/Composi\%C3\%A7\%C3\%A3o de Cinco Mulheres a partir da modelagem sist\%C3\%Aamica do Prel\%C3\%Badio n 1 para piano de Claudio Santoro 1 . Acesso em: 19/08/2020.

PITOMBEIRA, Liduino. Fundamentos teóricos e estéticos da modelagem sistêmica no âmbito da composição musical. In: Anais do $\mathbf{1 4}^{\circ}$ Colóquio de Pesquisa do PPGM/ UFRJ - Vol.2 - Processos Criativos - p.103-114. Rio de Janeiro, 2016. Disponível em: https://ppgmufri.files.wordpress.com/2016/12/anais-do-coloquio-14-vol-25. pdf. Acesso em: 08/09/2019. 
PITOMBEIRA, Liduino. Modelagem sistêmica do Ponteio N.2, Caderno 1, de Camargo Guarnieri a partir da teoria dos contornos, da teoria da variaçáo progressiva e da análise particional. In: $\mathbf{1 3}^{\circ}$ Colóquio de Pesquisa do Programa de Pós-Graduação em Música da UFRJ., 2015. Disponível em: https://ppgmufrj.files.wordpress. com/2016/06/09-pitombeira-modelagem-sistc3aamica-do-ponteio-no-2.pdf. Acesso em: 30/08/2020.

SCHUIJER, Michiel. Analyzing atonal music: pitch-class set theory and its contexts. University of Rochester Press, 2008.

STEWART, Ian. Em busca do infinito: Uma história da matemática dos primeiros números à teoria do caos. Tradução de George Schlesinger. Rio de Janeiro: Zahar, 2014.

STRAUS, Joseph Nathan. Introduçáo à teoria pós-tonal. 3.ed. Tradução de Ricardo Bordini. UNESP-EDUFBA, Salvador-São Paulo, 2013.

TAVARES, Pedro. Breve introduçáo a Teoria dos Conjuntos de Classes de Nota. 2020. Disponível em: https://www.academia.edu/41907195/Pedro_Tavares_Breve_introdu\%C3\%A7\%C3\%A3o a Teoria dos Conjuntos de Classes de Nota 2020 Acesso em: 18/08/2020. 